\title{
Prevalence and determinants of stillbirth among women attended deliveries in Aksum General Hospital: a facility based cross-sectional study
}

\author{
Tesfay Berhe ${ }^{1 *}$, Hailay Gebreyesus ${ }^{1}$ and Haftom Teklay ${ }^{2}$
}

\begin{abstract}
Objective: In Ethiopia skilled deliveries are increasing but stillbirth is not reducing as required. However; there are limited numbers of up to date studies done related to stillbirth in the study area. Therefore this was aimed to assess the prevalence and determinants of stillbirth using facility based cross-sectional study among women attended deliveries at Aksum General Hospital in 2018. Systematic random sampling method was used to select 573 study participants from the deliveries attended during the study period. The data was entered into Epi-data version 3.1 and exported to Statistical Package for Social Science version 21 for analysis. Bivariate and multivariable logistic regression analysis were conducted to identify significant predictors and strength of association was measured based on adjusted odds ratio with 95\% confidence level and statistical significance was declared at p-value less than 0.05 .
\end{abstract}

Results: The prevalence of stillbirth was 3.68\% in this study area. Maternal age $20-35$ ( $A O R=0.25 ; 95 \% \mathrm{Cl}(0.08,0.80)$ ), not using partograph $(\mathrm{AOR}=8.66 ; 95 \% \mathrm{Cl}(2.88,26.10))$ and gestational age $<37$ weeks $(\mathrm{AOR}=3.86 ; 95 \% \mathrm{Cl}(1.27$, 11.69)) were the independent factors affecting the stillbirth.

Keywords: Stillbirth, Delivered mothers, Aksum, Ethiopia

\section{Introduction}

Stillbirth is one of the adverse births outcomes and represent major problem in both developing and developed countries [1]. Developing countries are remained as the major contributors of stillbirth in which Ethiopia is among those in the higher prevalence [2-5]. It is also the reflections of quality of care during pregnancy and child birth; skilled deliveries are increasing but stillbirth is not well reducing as required in the developing world including Ethiopia [3-6].

There were 2.6 million stillbirths in 2015 worldwide [68]. Stillbirth due to intra-partum loss is higher in developing than developed countries which is $59 \%$ and $10 \%$ respectively. It has been noted that $99 \%$ of these deaths

\footnotetext{
*Correspondence: alnorasanti@gmail.com

1 Department of Public Health, College of Health Sciences, Aksum University, P. O. Box: 298, Aksum, Ethiopia

Full list of author information is available at the end of the article
}

occur in the low and middle income nations [9]. It is said that about $66 \%$ of the worldwide stillbirths is contributed by developing nations like India, Pakistan, Nigeria, China, Demographic Republic of Congo, Ethiopia, Bangladesh, Indonesia, Tanzania and Afghanistan. However, the stillbirth rate has come down by $19.4 \%$ from 2000 (1.02 million) to 2015 (2.6 million) with various interventions globally $[8,10]$.

In Ethiopia the stillbirth rate was 10.4, 16.9 and 11 per 1000 births in 2000, 2011 and 2016 [11, 12]. This shows that the progress on reducing stillbirth rate was poor. Under-5 mortality rates are reducing in many countries and Ethiopia also achieved the millennium development goal on child mortality reduction $[13,14]$. The government of Ethiopia had been implementing different effective programs so as to improve maternal and child health issues under the Health Extension Package like; immunization, community based nutrition, integrated management of Community Case Management on childhood 
illness and capacity building health professionals so as to improve the quality of service during pregnancy like; antenatal and delivery care [15]. However, the outcome during pregnancy and delivery periods is a major challenge in realizing the seated goal in the Sustainable Development Goals (SDGs) i.e. stillbirth and neonatal mortality shown less progress in Ethiopia [13, 14].

Thus, to reduce these problems, identifying the prevalence and factors that affect stillbirth in a setup is critically important. However, setup based information in the study area is limited. The aim of this study was to assess the prevalence and determinants of stillbirth among women attended deliveries at Aksum general hospital, Tigray, Northern Ethiopia in 2018.

\section{Main text \\ Methods \\ Study area and period}

The study was conducted from January to March 30, 2018 in Aksum town which is $1010 \mathrm{~km}$ away from north of Addis Ababa and $250 \mathrm{~km}$ far from Aksum (capital city of Tigray region). According to the town administrative office report 2019, the town has about 75,842 total populations, of which about $51 \%$ are female and $49 \%$ are male. Totally about 1759 deliveries were attended at Aksum general hospital in 2017. Administratively, the town is divided into five kebeles (the smallest administrative units). In the town there are two health centers, one general hospital, one referral hospital and four private clinics.

\section{Study design and populations}

This study was conducted by using facility based quantitative cross-sectional study design. Mothers who gave birth at Aksum general hospital who were randomly selected included in the study and those critically sick mothers who cannot respond during data collection were excluded from the study.

\section{Sample size and sampling techniques}

The sample size was determined by using single population proportion formula (i.e. $\left.n=z^{2} p(1-p) / d^{2}\right)$ using the following assumption: proportion of stillbirth $(\mathrm{p})=9.6 \%$, [16], margin of error (d) $=3 \%, 95 \%$ confidence level, design effect 2, using correction formula and $10 \%$ for possible non response rate. So the final sample size was 573. The first mother from the delivery register was identified using a lottery method. Then systematic random sampling technique was used to select study participants from the register within the general hospital.

\section{Operational definitions}

History of poor obstetric outcome: Mothers who had history of LBW, preterm birth, stillbirth, perinatal death or abortion.

Stillbirth: Stillbirth is a baby born with no signs of life at or after 28 weeks' gestation.

\section{Data collection tool}

A structured and quantitative interviewer administered questionnaire was adopted from $\mathrm{WHO}$ and different literatures [17, 18]. Data was collected from mothers using structured and pretested questionnaire. First the questionnaire was prepared in English and translated to local language Tigrigna and translated back to English to observe its consistency. Finally, the questionnaire was pre tested on $5 \%$ of mothers before the actual data collection in Adwa general hospital; correction and modification were done based on the gap identified during the pre-test interview.

\section{Data collection technique and quality control}

Interviewer-administered questionnaire were used for the data collection method. The data was collected by five clinical nurses and supervised by two BSc midwives professionals and the principal investigator. Training was given for data collectors and supervisors on the aim of the research, content of the questionnaire and how to conduct. Data on stillbirth was collected after the delivered mother was stabilized and before discharged to home. Additionally medical record of the mother was reviewed for the remaining data. The collected data was checked every day by supervisors and principal investigator for its completeness and consistency.

\section{Data processing and analysis}

The data was entered, cleaned and coded using Epi-data version 3.1 and was analyzed using SPSS version 21 . Descriptive statistics was used to present categorical data using frequency tables and bar graph. The association between dependent and each independent factor was analyzed using bivariate logistic regression model with crude odds ratio and 95\% confidence interval. Factors with $\mathrm{p}$-value $<0.25$ were further analyzed using multivariable logistic regression analysis to determine factors associated with stillbirth. Finally p-value at $<0.05$ was used to declare the significant associated factors with the outcome variable (stillbirth). Hosmer and Lemeshow goodness-of-fitness was also used to test model fitness. In addition multi-collinearity between independent variables was also checked. 


\section{Results}

\section{Socio-demographic and economic characteristics} of respondents

A total of 570 mothers were interviewed which gives 99.5\% of response rate. Four hundred forty-three (77.7\%) of the study participants were in the age group of 20-34 years and 547 (96\%) were Orthodox followers. Most of the respondents $(n=542 ; 95.1 \%)$ were Tigrean by ethnicity and 550 (96.5\%) were married. Four hundred eighty-nine $(86 \%)$ of the study participants were lived with family size of below five and two hundred thirtyseven (41.6\%) had monthly income of 2500-5000 Ethiopian birr (Table 1).

\section{Table 1 Socio-demographic characteristics of respondents assessed on stillbirth in Aksum hospital, Tigray, Ethiopia,} $2018(n=570)$

\begin{tabular}{|c|c|c|}
\hline Variables & Number & Percent \\
\hline \multicolumn{3}{|l|}{ Maternal age in years } \\
\hline$<20$ & 68 & 11.9 \\
\hline $20-34$ & 443 & 77.7 \\
\hline $35+$ & 59 & 10.4 \\
\hline \multicolumn{3}{|l|}{ Residence } \\
\hline Urban & 531 & 93.2 \\
\hline Rural & 39 & 6.8 \\
\hline \multicolumn{3}{|l|}{ Marital status } \\
\hline Single & 20 & 3.5 \\
\hline Married & 550 & 96.5 \\
\hline \multicolumn{3}{|l|}{ Religion } \\
\hline Orthodox & 547 & 96 \\
\hline Muslim & 23 & 4 \\
\hline \multicolumn{3}{|l|}{ Ethnicity } \\
\hline Tigrean & 542 & 95.1 \\
\hline Others $^{\mathrm{a}}$ & 28 & 4.9 \\
\hline \multicolumn{3}{|c|}{ Maternal educational status } \\
\hline Illiterate & 56 & 9.8 \\
\hline Elementary & 177 & 31.1 \\
\hline Secondary and above & 337 & 59.1 \\
\hline \multicolumn{3}{|l|}{ Maternal occupation } \\
\hline Housewife & 345 & 60.5 \\
\hline Daily laborer & 25 & 4.4 \\
\hline Employed & 87 & 15.3 \\
\hline Merchant & 82 & 14.4 \\
\hline Student & 31 & 5.4 \\
\hline \multicolumn{3}{|l|}{ Monthly income } \\
\hline$<2500$ birr & 126 & 22.1 \\
\hline $2500-5000$ & 237 & 41.6 \\
\hline$>5000$ & 207 & 36.3 \\
\hline \multicolumn{3}{|l|}{ Family size } \\
\hline$<5$ & 489 & 85.8 \\
\hline$\geq 5$ & 81 & 14.2 \\
\hline
\end{tabular}

NB: Others ${ }^{\mathrm{a}}$ Amhara and Afar

\section{Gynecological and obstetrical, and newborn related} characteristics of respondents

From the total respondents 372 (65.3\%) were multipara, and $234(62.9 \%)$ gave birth between 2 and 5 years from previous pregnancy. Most of the mothers 469 (82.3\%) were received ANC four times and above and 459 (80.7\%) initiated ANC at first trimester of the current pregnancy. Most of the pregnancies $(n=529 ; 92.8 \%)$ were planned and $556(97.5 \%)$ mothers were not faced any pregnancy related complication during current pregnancy. Regarding history of poor obstetric outcome, 115 (20.2\%) of participants had faced any history of poor obstetric outcome in their previous pregnancies. The finding of this study showed that the prevalence of stillbirth was $3.68 \%$ (Table 2).

\section{Factors associated with stillbirth}

According the binary logistic regression maternal age, gestational age, antenatal care, counseling on additional diet during pregnancy, additional diet during pregnancy and partograph use were showed significant association with stillbirth at $\mathrm{p}$-value $<0.05$.

In multiple variable logistic regressions analysis, after controlling all other variables ante natal care, counseling on additional diet during pregnancy and additional diet during pregnancy were not significantly associated with stillbirth. But maternal age, gestational age and partograph use had shown significant association with stillbirth.

Newborn infant from mothers aged 20-35 were 4 times less likely to be stillbirth as compared to mothers in the age group $\geq 35$ (AOR $=0.25 ; 95 \%$ CI (0.08, $0.80)$ ) and mothers who didn't monitored with partograph were almost 9 times more likely to give stillbirth compared these monitored by partograph $(\mathrm{AOR}=8.66$; 95\% CI $(2.88,26.10))$. Regarding gestational age newborn infant who were born in $<37$ weeks of gestational age were almost 4 times more likely to be stillbirths compared to these who born $\geq 37$ weeks of gestational age $(\mathrm{AOR}=3.86 ; 95 \% \mathrm{CI}(1.27,11.69))$ (Table 3$)$.

\section{Discussion}

According the findings of this study prevalence of stillbirth was $3.68 \%$. The prevalence of stillbirth is almost consistent with a study conducted in Nigeria which shows $4 \%$ prevalence [19]. Whereas lower than the studies conducted at Shire hospital, Dessie referral hospital, Gondar university hospitals and Ngest Eleni Mohammed memorial general hospital and which shows 9.6\%, 14\%, $7.1 \%$ and $9.8 \%$ respectively. The variations between these findings may be attributable to the variations in socioeconomic variations of the study subjects in whom most of 
Table 2 Gynecological and obstetric, and newborn characteristics of respondents Aksum hospital, Tigray, Ethiopia, $2018(n=570)$

\begin{tabular}{|c|c|c|}
\hline Variables & Frequency & Percent \\
\hline \multicolumn{3}{|l|}{ ANC visit } \\
\hline Less than four & 101 & 17.7 \\
\hline Four and above & 469 & 82.3 \\
\hline \multicolumn{3}{|l|}{ Initiation of ANC } \\
\hline First trimester & 459 & 80.7 \\
\hline Second trimester & 105 & 18.4 \\
\hline Third trimester & 5 & 0.9 \\
\hline \multicolumn{3}{|l|}{ Parity } \\
\hline Prim-gravid & 198 & 34.7 \\
\hline Multi gravid & 372 & 65.3 \\
\hline \multicolumn{3}{|l|}{ Pregnancy type } \\
\hline Singleton & 563 & 98.8 \\
\hline Multiple & 7 & 1.2 \\
\hline \multicolumn{3}{|l|}{ Mode of delivery } \\
\hline SVD & 488 & 85.6 \\
\hline Assisted delivery & 20 & 3.5 \\
\hline Cesarean section & 62 & 10.9 \\
\hline \multicolumn{3}{|l|}{ Birth interval (years) } \\
\hline$<2$ & 46 & 12.4 \\
\hline $2-5$ & 234 & 62.9 \\
\hline$>5$ & 92 & 24.7 \\
\hline \multicolumn{3}{|l|}{ Pregnancy status } \\
\hline Planned & 529 & 92.8 \\
\hline Unplanned & 41 & 7.2 \\
\hline \multicolumn{3}{|l|}{ Partograph use } \\
\hline Yes & 500 & 87.7 \\
\hline No & 70 & 12.3 \\
\hline \multicolumn{3}{|l|}{ Labor status } \\
\hline Spontaneous & 528 & 92.6 \\
\hline Induced & 42 & 7.4 \\
\hline \multicolumn{3}{|c|}{ History of poor obstetric outcome } \\
\hline Yes & 115 & 20.2 \\
\hline No & 455 & 79.8 \\
\hline \multicolumn{3}{|c|}{ Pregnancy related complication } \\
\hline Yes & 14 & 2.5 \\
\hline No & 556 & 97.5 \\
\hline \multicolumn{3}{|c|}{ Hemoglobin level (mg/dl) } \\
\hline$<11$ & 26 & 4.6 \\
\hline$\geq 11$ & 544 & 95.4 \\
\hline \multicolumn{3}{|l|}{ Labor complication } \\
\hline Yes & 68 & 11.9 \\
\hline No & 502 & 88.1 \\
\hline \multicolumn{3}{|l|}{ Birth outcome } \\
\hline Stillbirth & 21 & 3.68 \\
\hline Live birth & 549 & 96.32 \\
\hline
\end{tabular}

our study participants were urban residents which may resulted in improved birth outcome [16, 20-22].

Mothers' age was significantly associated with stillbirth in this study. Newborn infant from mothers aged 20-35 years were $75 \%$ times less likely vulnerable to stillbirth as compared to newborn infants from mothers in the age group $\geq 35$ years. This study is consistent with a logistic regression analysis on determinants of stillbirth in Ethiopia, Tanzania and systemic review conducted by Canadian medical association and its licensors [23-25]. The reasons that stillbirth rates increase with maternal age are currently unclear. Even in uncomplicated pregnancies there is increased risk in stillbirth associated with maternal age. In older mothers, stillbirth rate increases as the gestational age increases beyond 37 weeks [26].

Newborn born before 37 weeks of gestational age are with increased risk of stillbirth. This is consistent with study conducted in Tanzania [24]. This association might be due to premature. Immature newborns have less time to grow in the mother's uterus and they are at risk of being asphyxiated and distressed and lead them to stillbirth [21].

Partograph utilization by service providers was the other strong factor associated with stillbirth. Participants who were not served using partograph were in higher odds of facing stillbirth than their counter parts. Poor partograph utilization may resulted in prolonging second stage of labor which could also resulted in depriving interventions like; cesarean section, augmentation and instrumental delivery [26-28].

\section{Conclusion}

Based on this study stillbirth prevalence was high. Factors like maternal age $\geq 35$ years, gestational age $<37$ weeks and lack of partograph use during delivery also associated with stillbirth. The determinants identified in this study can be prevented and managed by providing appropriate care during ante-partum and intra-partum period.

\section{Limitation of the study}

This study was conducted within single pubic hospital on limited number of participants (small sample size) where at delivery clinic which means the finding may not be generalizable to the overall Ethiopian delivered mothers in this or other public or private clinics. This cross sectional nature of the data shares the weakness of cross sectional study. It is impossible to draw inferences about the 
Table 3 Factors associated with stillbirth among deliveries at Aksum hospital, Tigray, Northern Ethiopia, 2017 $(n=570) 390$

\begin{tabular}{|c|c|c|c|c|c|}
\hline \multirow[t]{2}{*}{ Variables } & \multicolumn{2}{|l|}{ Stillbirth } & \multirow[t]{2}{*}{ COR (Cl-95\%) } & \multirow[t]{2}{*}{ AOR (Cl-95\%) } & \multirow[t]{2}{*}{$p$-value } \\
\hline & $\begin{array}{l}\text { Yes } \\
\text { n (\%) }\end{array}$ & $\begin{array}{l}\text { No } \\
\text { n (\%) }\end{array}$ & & & \\
\hline \multicolumn{6}{|l|}{ Maternal age } \\
\hline$<20$ & $3(4.4)$ & 65 (95.6) & $0.41(0.10-1.71)$ & $0.36(0.07-1.89)$ & 0.28 \\
\hline $20-35$ & $12(2.7)$ & $431(97.3)$ & $0.25(0.09-0.68)$ & $0.25(0.08-0.80)^{*}$ & 0.023 \\
\hline$\geq 35$ & $6(10.2)$ & $53(89.8)$ & 1 & 1 & \\
\hline \multicolumn{6}{|l|}{ ANC visit } \\
\hline Less than four & $9(8.9)$ & $92(91.1)$ & 1 & 1 & \\
\hline Four and above & $12(2.6)$ & $457(97.4)$ & $0.27(0.11-0.66)$ & $0.41(0.13-1.30)$ & 0.116 \\
\hline \multicolumn{6}{|l|}{ Arrival at HF } \\
\hline Before onset of labor & $5(6)$ & $78(94)$ & $1.887(0.67-5.30)$ & $1.51(0.39-5.91)$ & \\
\hline After onset of labor & $16(3.3)$ & $471(96.7)$ & 1 & 1 & \\
\hline \multicolumn{6}{|l|}{ Baby's sex } \\
\hline Male & $15(4.9)$ & $292(95.1)$ & $2.2(0.84-5.76)$ & $1.657(0.58-4.75)$ & \\
\hline Female & $6(2.3)$ & $257(97.7)$ & 1 & 1 & \\
\hline \multicolumn{6}{|l|}{ Partograph use } \\
\hline Yes & $10(2)$ & $490(98)$ & 1 & 1 & \\
\hline No & $11(15.7)$ & $59(84.3)$ & $9.14(3.72-22.42)$ & $8.66(2.88-26.10)^{*}$ & 0.001 \\
\hline \multicolumn{6}{|l|}{ Gestational age } \\
\hline$<37$ weeks & $10(13.9)$ & $62(86.1)$ & $7.14(2.91-17.50)$ & $3.86(1.27-11.69)^{*}$ & 0.011 \\
\hline$\geq 37$ weeks & $11(2.2)$ & $487(97.8)$ & 1 & 1 & \\
\hline \multicolumn{6}{|l|}{ Counseling on diet } \\
\hline Yes & $9(2.3)$ & $389(97.7)$ & 1 & 1 & \\
\hline No & $12(7)$ & $160(93)$ & $3.24(1.34-7.84)$ & $9.94(0.80-124.12)$ & 0.085 \\
\hline \multicolumn{6}{|l|}{ Additional diet } \\
\hline Yes & $10(2.5)$ & 385 (97.5) & 1 & 1 & \\
\hline No & $11(6.3)$ & $164(93.7)$ & $2.58(1.08-6.20)$ & $0.19(0.14-2.51)$ & 0.225 \\
\hline
\end{tabular}

$A O R$ adjusted odds ratio, $\mathrm{Cl}$ confidence interval, COR crude odds ratio

1: referent

*Significant at $\mathrm{p}$-value $<0.05$

direction of relations among study variables. These data are retrospective and thus are subject to recall bias. Then the currently reported prevalence may under estimate the real prevalence in the ground.

\section{Abbreviations}

AOR: adjusted odds ratio; BSc: Bachelor of Science; COR: crude odds ratio; EDHS: Ethiopian Demographic and Health Survey; HF: health facility; km: kilometer; LBW: low birth weight; MUAC: Middle Upper Arm Circumference; SPSS: Statistical Package for Social Science; USA: United States of America; WHO: World Health Organization.

\section{Acknowledgements}

Our heartfelt thank goes to Aksum University for financial support. We are thankful to Aksum hospital staff for their positive responses to facilitate the study and all study participants who voluntarily participated in this study.

\section{Authors' contributions}

TB wrote the proposal, participated in data collection, analyzed the data, and drafted the paper. HG and HT approved the proposal, participated in data analysis and revised subsequent drafts of the paper. All authors read and approved the final manuscript.

\section{Funding}

This work was funded by Aksum University College of Health Science.

Availability of data and materials

The datasets in which conclusion taken is available in the form of Microsoft Excel. It is available on requesting.

\section{Ethics approval and consent to participate}

Ethical approval and clearance were obtained from Aksum University, College of Health science, Research Ethics Committee. Permission letter was also obtained from Aksum health office and was presented to all participants. Written consent was obtained after the potential participants were informed of the study's objectives and reading the information sheet. Only women who gave consent to participate were included in the study. All participants were also informed that they could withhold or withdraw from participation at any time, without any negative consequences. Interviews were conducted in private that guarantee optimum privacy. Confidentiality and privacy of the study were maintained during data collection, analysis, and reporting. 


\section{Consent for publication}

Not applicable.

\section{Competing interests}

The authors declare that they have no competing interests.

\section{Author details}

${ }^{1}$ Department of Public Health, College of Health Sciences, Aksum University, P. O. Box: 298, Aksum, Ethiopia. ${ }^{2}$ JSI/L10K, Mekelle, Ethiopia.

Received: 3 April 2019 Accepted: 22 June 2019

Published online: 01 July 2019

\section{References}

1. Eshete A, Birhanu D, Wassie B. Birth outcomes among laboring mothers in selected health facilities of north Wollo zone, Northeast Ethiopia: a facility based cross-sectional study. Health. 2013;5(07):1141.

2. Ashish KC, et al. Risk factors for antepartum stillbirth: a case-control study in Nepal. BMC Pregnancy Childbirth. 2015;15:146.

3. Gebreslasie K. Preterm birth and associated factors among mothers who gave birth in Gondar Town Health Institutions. Adv Nurs. 2016:2016:4703138

4. Taye M, Afework M, Fantaye W, Diro E, Worku A. Magnitude of birth defects in Central and Northwest Ethiopia from 2010-2014: a descriptive retrospective study. PLOS ONE. 2016;11(10):e0161998.

5. Mekonen HK, Nigatu B, Lamers WH. Birth weight by gestational age and congenital malformations in Northern Ethiopia. BMC Pregnancy Childbirth. 2015;15:76.

6. Lawn JE, Blencowe H, Waiswa P, Amouzou A, Mathers C, Hogan D, et al. Stillbirths: rates, risk factors, and acceleration towards 2030. Lancet. 2016:387(10018):587-603.

7. Aminu M, Unkels R, Mdegela M, Utz B, Adaji S, Van Den Broek N. Causes of and factors associated with stillbirth in low- and middle-income countries: a systematic literature review. BJOG. 2014;121:141-53.

8. Lakshmi ST, Thankam U, Jagadhamma P, Ushakumari A, Chellamma N, Hariharan SV. Risk factors for still birth: a hospital based case control study. Int J Reprod Contracept Obstet Gynecol. 2017;6(3):970-4.

9. World Health Organization. World health statistics 2016: monitoring health for the SDGs sustainable development goals. World Health Organization; 2016.

10. Blencowe H, Cousens S, Jassir FB, Say L, Chou D, Mathers C, Lancet Stillbirth Epidemiology Investigator Group, et al. National, regional, and worldwide estimates of stillbirth rates in 2015, with trends from 2000: a systematic analysis. Lancet Glob Health. 2016:4(2):98-108.

11. Central Statistical Agency [Ethiopia] and ICF International. Ethiopia demographic and health survey 2011. Addis Ababa: Central Statistical Agency and ICF International; 2012.

12. Agency CS. Ethiopia demographic and health survey 2016. Maryland: The DHS Program ICF; 2017.

13. Lawn JE, Cousens S, Zupan J. Neonatal survival 1.4 million neonatal deaths: when? where? why? Lancet. 2009;2005(365):891-900.
14. Black RE, Cousens S, Johnson HL, Lawn JE, Rudan I, Bassani DG, et al. Global, regional, and national causes of child mortality in 2008: a systematic analysis. Lancet. 2010;375(9730):1969-87.

15. Mason JB, Saldanha LS, Ramakrishnan U, Lowe A, Noznesky EA, Girard AW McFarland DA, Martorell R. Opportunities for improving maternal nutrition and birth outcomes: synthesis of country experiences. Food Nutr Bull. 2012;33(2_suppl1):S104-37.

16. Tesfay A, Abera H. Brhane G. Assessment of magnitude and associated factors of adverse birth outcomes among deliveries at Suhul Hospital Shire, Tigray, Ethiopia From September, 2015 to February, 2016. Biomed J Sci Tech Res. 2017. https://doi.org/10.26717/BJSTR.2017.01.000619

17. Reinebrant HE, Leisher SH, Coory M, Henry S, Wojcieszek AM, Gardener $\mathrm{G}$, et al. Making stillbirths visible: a systematic review of globally reported causes of stillbirth. BJOG. 2018;125(2):212-24.

18. Goldenberg RL, McClure EM, Bhutta ZA, Belizán JM, Reddy UM, Rubens CE, Mabeya H, Flenady V, Darmstadt GL, Lancet's Stillbirths Series steering committee. Stillbirths: the vision for 2020. Lancet. 2011;377(9779):1798-805.

19. Suleiman BM, Ibrahim HM, Abdulkarim N. Determinants of stillbirths in Katsina, Nigeria: a hospital-based study. Pediatr Rep. 2015;7:5615.

20. Cherie N, Mebratu A. Adverse birthout comes and associated factors among delivered mothers in Dessie Referral Hospital, North East Ethiopia. J Women's Health Reprod Med. 2017;1(1):4.

21. Adane AA, Ayele TA, Ararsa LG, Bitew BD, Zeleke BM. Stillbirths among deliveries at Gondar University Hospital, Northwest Ethiopia. BMC Pregnancy Childbirth. 2014;14:90.

22. Abdo RA, Endalemaw TB, Tesso FY. Prevalence and associated factors of adverse birth outcomes among women attended maternity ward at Negest Elene Mohammed Memorial General Hospital in Hosanna Town, SNNPR, Ethiopia. J Womens Health Care. 2016;5(4):324.

23. Huang L, Sauve R, Birkett N, Fergusson D, van Walraven C. Maternal age and risk of stillbirth: a systematic review. CMAJ. 2008;178(2):165-72.

24. Chuwa FS, Mwanamsangu AH, Brown BG, Msuya SE, Senkoro EE, Mnali OP, Mazuguni F, Mahande MJ. Maternal and fetal risk factors for stillbirth in Northern Tanzania: a registry-based retrospective cohort study. PLoS ONE. 2017;12(8):e0182250.

25. Berhie KA, Gebresilassie HG. Logistic regression analysis on the determinants of stillbirth in Ethiopia. Matern Health Neonatol Perinatol. 2016;2:10.

26. Ahmed B, Jain $M$, Bharwani $H$. Partograph versus no partograph: effect on labour progress and delivery outcome: a comparative study. Int J Reprod Contracept Obstet Gynecol. 2017;6(11):4928-33.

27. Kitila SB, et al. Utilization of partograph during labour and birth outcomes at Jimma University. J Pregnancy Child Health. 2014;1(1):101.

28. Ashish $\mathrm{KC}$, et al. Inadequate fetal heart rate monitoring and poor use of partogram associated with intrapartum stillbirth: a case-referent study in Nepal. BMC Pregnancy Childbirth. 2016;16:233.

\section{Publisher's Note}

Springer Nature remains neutral with regard to jurisdictional claims in published maps and institutional affiliations.

Ready to submit your research? Choose BMC and benefit from

- fast, convenient online submission

- thorough peer review by experienced researchers in your field

- rapid publication on acceptance

- support for research data, including large and complex data types

- gold Open Access which fosters wider collaboration and increased citations

- maximum visibility for your research: over $100 \mathrm{M}$ website views per year

At $\mathrm{BMC}$, research is always in progress.

Learn more biomedcentral.com/submissions 